\title{
BERGSON E KANT: O PROBLEMA DO TEMPO E OS LIMITES DA INTUIÇÃO
}

\begin{abstract}
Aristeu L. C. Mascarenhas ${ }^{1}$
Resumo: Este texto tem por objeto a análise da intuição, das especificidades das definiçôes bergsonianas e suas distinçôes em relação à visão moderna, sobretudo da doutrina kantiana, buscando mostrar os pontos de rompimento e avanço de Bergson em relação a essa concepção. O que se nota, em um primeiro momento, é como a obra de Bergson está de certo modo intimamente ligada a alguns temas clássicos da teoria do conhecimento já amplamente trabalhados na obra de Kant, razão pela qual esse autor está presente desde o início de seu pensamento, desde o Ensaio sobre os dados da consciência, estendendo-se mesmo por quase todo o conjunto de sua obra. De fato, se se abordar os textos de Bergson pela sua referência à história da filosofia, será Kant, sem dúvida, que aparecerá como seu grande interlocutor; na maior parte das vezes como contrapondo a uma crítica que pode ser estendida a toda tradição filosófica, sobretudo àquela que teria subjugado a metafísica aos métodos e orientaçôes da ciência. É natural, com efeito, que o autor da Crítica da Razão Pura surja como personagem importante na obra de Bergson. O pensamento de Kant está assentado em um momento importante quanto aos "rumos" da filosofia, especialmente no que diz respeito ao alcance da metafísica. E, se Bergson expressara, em sua doutrina, todo um esforço para reaver o lugar de direito da metafísica, ampliando mesmo, para além dos limites da análise científica, seu alcance, é certamente Kant que ele haveria de encontrar em suas investigaçóes.
\end{abstract}

Palavras-Chave: Bergson. Kant. Intuição. Tempo real. Metafísica.

A abordagem de um tema como o do conhecimento no pensamento de Bergson requer, antes, um olhar atento para sua teoria da intuição, o que em nada facilita a empresa, pois a compreensão desse termo e, consequentemente, de outros a ele ligados, vê-se obscurecida pelo fato de o mesmo se mostrar sob uma diversidade significativa na história do pensamento, que dificulta a extraçáo de um sentido comum a partir do qual se poderia buscar uma aproximação conceitual segura.

De fato, por maiores que sejam as afinidades eletivas entre autores e correntes da tradição filosófica, no que toca à intuição, certamente não se pode dizer que haja uma teoria geral desse conceito aceita de forma unânime. Daí a hesitação confessa do autor francês em relação à adoção do termo, na sua

\footnotetext{
${ }^{1}$ Professor do Departamento de Ciências Humanas e Letras da Universidade Estadual do Sudoeste da Bahia; Doutor em Filosofia pela Universidade Federal de São Carlos-UFSCar; Mestre em Filosofia pela Universidade Estadual Paulista-UNESP. E-mail: laumascarenhas@gmail.com
}

http://dx.doi.org/10.1590/S0101-31732017000200006 
filosofia; ${ }^{2}$ e, também, as tentativas recorrentes, ao longo de seus textos, de fornecer uma caracterização própria, que o distinga do seu emprego na tradição moderna, sobretudo do emprego kantiano que, ao limitar a intuição ao seu uso sensível, promovera a separação entre ciência e metafísica, deixando como prejuízo para a filosofia a renúncia ao contato com o absoluto (LEOPOLDO E SILVA, 1983, p. 20). Ver-se-á, com efeito, que tal separação, acompanhada da busca da unidade do conhecimento na ciência, será, para Bergson, um problema central na filosofia kantiana e, de modo mais geral, em toda a tradição moderna.

Enfim, é praticamente impossível se aproximar do pensamento de Bergson sem que se veja surgir, o tempo todo, em sua obra, a intuição em seu uso como método imanente de uma filosofia que advoga a possibilidade do acesso integral aos objetos, razáo pela qual esse conceito assume aqui certa ubiquidade.

Defensor de uma metafísica capaz de conduzir ao conhecimento absoluto da realidade, principalmente no âmbito da consciência, da vida, enfim, da duração, Bergson se coloca, desde os primeiros escritos, na contramáo da modernidade, em especial da tradição kantiana, na qual predomina como modelo a análise científica. $\mathrm{Na}$ tradição instaurada pelo autor alemão, as pretensôes do conhecimento veem-se reduzidas pela determinação das possibilidades e dos limites próprios da razão. Sua crítica acentua-se, mais ainda, porque a filosofia kantiana, ao fazer valer uma "[...] ciência uma e integral, abarcando a totalidade do real" (BERGSON, 2005, p. 384) e, ao buscar nessa mesma ciência a unidade do saber, teria feito "[...] economia da hipótese metafísica” (LEOPOLDO E SILVA, 1983, p. 21), preconizando, com isso, a inacessibilidade da coisa em si. A raiz dessa censura bergsoniana à tradição filosófica, assim como a Kant, está fundada, sobretudo, em torno dos conceitos de tempo e intuição. E, mais especificamente, no caso da intuição, a raiz do problema estaria assentada em uma insuficiente ou falsa abordagem do tempo real, o qual Bergson reconceitua como duraçâo, após criticar a tradição por haver confundido o tempo com o espaço.

A questão que se impôe a Bergson, portanto, é esta: o que é a duração, então? Em que consiste a concepção bergsoniana do tempo? Ao longo de suas obras, buscando fugir da definição de algo aparentemente indefinível

${ }^{2}$ Uma exposição mais detalhada dos motivos dessa hesitação pode ser vista no artigo de Camille Riquier: Intuition et méthode che Bergson. Revue trans-paraître: l'intuition. Premier numéro, p.189$218,2007$. 
ou mesmo da generalização do que é singular, movente, Bergson aumenta consideravelmente os termos e as expressôes, para referir-se à duração. Para enumerar aqui alguns, aparecem: criação, indivisibilidade, continuidade, sucessão, interpenetrabilidade das partes, movimento, dinamismo, novidade, heterogeneidade, imprevisibilidade, irreversibilidade. Essa abundância de referências, por sua vez, traz aos leitores a sensação de uma diversidade quase infinita de "imagens" da duração. A saída encontrada por Worms, por exemplo, será propor três visóes desse conceito, as quais auxiliam na captação de seu sentido fundamental: ele o toma a partir das ideias de constituiçáo, continuidade e sucessão (WORMS, 2000, p. 20). Com efeito, a duração constitui, ou seja, produz novidade, ela é criação constante, sendo, por isso mesmo, irreversível e imprevisível. Em seu movimento, surpreende, produzindo um futuro inassimilável ao passado. Há uma distinção de suas partes entre si, são heterogêneas. Porém, por se interpenetrarem, se confundirem e estenderem seus limites em uma duração indivisível e contínua, até os limites umas das outras, essas partes, por mais heterogêneas que sejam, não deveriam, com efeito, ser chamadas partes. Por último, aparece a sucessão, que é, finalmente, o aspecto dinâmico e móvel da duração, sua mobilidade, seu movimento contínuo.

Olhando além dessas três caracterizaçooes fundamentais, a duração aponta três dimensóes. Em primeiro lugar, no Ensaio sobre os dados imediatos da consciência, a duração aparece como a essência da consciência, o fluir dos nossos estados mentais, o eu em seu devir. Posteriormente, em Introdução à Metafísica, Bergson afirmará que o âmbito em que, por excelência, se revela a duração é o âmbito do eu (BERGSON, 2006, p. 188). Assim, o que se pode dizer é que a duração é, primeiramente, uma realidade psicológica. Porém, esse posicionamento é de ordem epistêmica. O eu está presente ali onde a duração aparece pela primeira vez; aparece onde é inegável. Logo, a preeminência vislumbrada pelo fato de que a duração como realidade psicológica governa o primeiro livro de Bergson é uma preeminência de ordem cronológica: a duraçấo como essência do eu é o primeiro sentido da duração que surge na obra de Bergson. Pode-se assinalar, então, que a duração é, primeiramente, uma realidade psicológica, porém, somente no sentido cronológico e epistêmico. A partir "[...] de la durée 'intérieure' ou 'psychologique' à laquelle chacun de nous a accès de manière immanente em lui-même, il faut donc concevoir par um élargissement successif une diversité de durées correspondant aux divers degrés de l'être." (WORMS, 2000, p. 21). A duração interior é, assim, a primeira que se pode perceber. Contudo, com base nela, pode-se divisar 
uma duração prévia, no sentido lógico: a duração em um sentido ontológico, posterior na obra de Bergson. Note-se que, em A Evolução Criadora, a duração aparece como a própria dinâmica do ser. Dessa perspectiva, o que se pode ver é que, da duração como realidade psicológica, passa-se à duração como realidade ontológica: é o "salto na ontologia", como frisa Deleuze (1999, p 44). ${ }^{3}$ Se por um lado, ao tempo Bergson assimila duração e espírito, por outro, a duração se assimila ao espirito. Toda essa especulação sobre as "imagens" da duração náo deve, contudo, esconder o seu sentido mais elementar: a duraçáo é o tempo. A duração é, pois, o nome que Bergson atribuíra ao que a tradição e o senso comum chamam de tempo, para com isso distinguir a sua noção dessas duas instâncias. A duração é o tempo real, o devir. Com efeito, ela é sucessão, continuidade e constituiçâo, criação de incessante novidade, é o tempo em seu escoamento. Têm-se, assim, três dimensôes para a duração: ela é eu, ser e tempo.

Mas por que Bergson dá ao tempo o nome duração? Por que sente essa obrigação de distinguir-se da tradição? A resposta parece estar na recorrente crítica dispensada à história da filosofia: ter confundido tempo com espaço. Haver pensado o tempo como o espaço, como um meio homogêneo. Homogêneo é o espaço, afirma Bergson. O tempo, cujos momentos presentes se distinguem do passados e do porvir, todo o tempo náo pode ser meio homogêneo. E quando Bergson se menciona o tempo pensado como espaço, esse tempo "impuro", contaminado de imagens do espaço, se refere a ele como “tempo homogêneo". É preciso ver que a homogeneidade do espaço é a condição mesma de sua divisibilidade. Ao ser todo igual, o espaço abre-se para divisão, para o corte, a fragmentação, podendo, no entanto, unir-se novamente, recompor-se. Já o tempo, sendo absolutamente heterogêneo, é todo contínuo, simples, indivisível. Esta é, entâo, a grande crítica à filosofia moderna: ter pensado o tempo como o espaço, isto é, como homogêneo e divisível. O erro,

\footnotetext{
${ }^{3}$ Deleuze distingue, através da análise da diferença de natureza entre passado e presente, de um lado, o nível transcendental ou ontológico e, de outro, o nível empírico ou psicológico. Para ele, o que está em evidência nessa distinçâo é a forma com que o pensamento bergsoniano implica um salto na ontologia. Sai-se, com efeito, de um presente, o qual é psicológico, para se colocar no ser em si do passado, que é pura ontologia. É certo que, em função da utilidade, é preciso que se opere um movimento vetorialmente inverso, quando a lembrança ganha existência psicológica e se insere no presente, forçando a atualização, mas mudando de natureza. Nesse processo de "psicologização", de virtual, passa a lembrança ao estado atual; acontece pouco a pouco uma "encarnaçấo" do passado, que sai do seu ser impassível e se insere no nível empírico. Há, como se pode notar, a descriçẫo de um passado, em geral, que não se confunde com um passado particular, de um presente que foi, mas se apresenta mesmo como um elemento ontológico a partir do qual se pode pensar a passagem do tempo, a passagem de todo presente particular mediante atualização.
} 
contudo, teria começado com Zenon ${ }^{4}$, que suportara seus paradoxos nessa confusão, mas teria se prolongado e se alimentado, fundamentalmente, em Kant.

Com efeito, desde o Ensaio, Kant aparece como um dos principais responsáveis pela subsunção da filosofia ou da metafísica aos ideais e métodos que animam a pesquisa científica; ideais e métodos que estariam marcados, sobretudo, pelo tratamento do tempo a partir de uma terminologia herdada da investigação do espaço. De fato, esse texto de Bergson mostra-se, em muitos aspectos, como esforço de revisão da Estética transcendental kantiana (LEOPOLDO E SILVA, 1983 p. 23) , com base no estabelecimento de um novo estatuto para o espaço e, principalmente, para o tempo (como duração) dentro do quadro da cognição humana. O que se pode observar é que Bergson coloca em questáo os resultados obtidos na Crítica kantiana a despeito do tempo como forma do sentido interno. Dessa forma, esse tempo (formal) será condição mesma para toda experiência possível, interior e exterior. Em outras palavras, é através dele que se poderá intuir a si mesmo (imediatamente) e ao mundo (mediatamente) - o tempo como condição subjetiva da intuição ou condição necessária de toda experiência (interna e externa). Assim, se, na Estética, o autor alemão define a intuição por suas duas formas puras e a priori, espaço e tempo - hipostasiando o tempo como uma forma pura interna da experiência e o espaço como meio exterior de apresentação da realidade fenomênica à experiência -, em contrapartida, Bergson, no Ensaio, se referirá ao tempo como duração qualitativa e heterogênea da experiência interna; e, ao espaço, como meio homogêneo no qual se "desenrolariam" os estados materiais.

Se, na definição de espaço, no seu primeiro livro, salvo diferenças específicas, Bergson parece corroborar a descrição kantiana, ${ }^{6}$ no que diz respeito ao tempo, a distinção se delineia e o rompimento é muito mais profundo. Essa

\footnotetext{
${ }^{4}$ Um exemplo dessa confusão em torno do tempo em Zenon é o clássico paradoxo da flecha. Nesse paradoxo, lança-se uma flecha. Em cada momento, no tempo, a flecha está em uma posição específica e, se esse momento é pontual, a flecha não tem tempo para se mover, posto que está em repouso nesse instante. Ora, durante os períodos de tempo seguintes, a flecha também estará em repouso pelo mesmo motivo. Desse modo, a flecha está sempre em repouso: o movimento é impossível.

${ }^{5}$ Essa leitura já aparece, também, na interpretação de Bento Prado Júnior, sobretudo ao explicitar a distinção entre duas formas de multiplicidades como uma das condiçōes para determinação da duração. Ali, segundo ele, o texto bergsoniano teria a pretensão de ser a "[...] definitiva redação da estética transcendental, para além dos equívocos da estética kantiana.” (PRADO JÚNIOR, 1989, p. 89).

${ }^{6}$ Bergson mostra que há, na Estética, a apresentação do espaço como "[...] uma realidade tâo sólida quanto essas sensaçóes, ainda que de outra ordem." (BERGSON, 1988, p. 67). E completa: "Para que o espaço nasça da coexistência, é necessário um acto do espírito que as abranja a todas simultaneamente
} 
crítica aparece de modo explícito, quando, por exemplo, ele afirma: "O erro de Kant foi tomar o tempo por um meio homogêneo. Parece não ter notado que a duração real compóe-se de momentos interiores relativamente uns aos outros, e se adquire a forma de um todo homogêneo é porque se exprime no espaço." (BERGSON, 1988, p. 159). Kant teria confundido, assim, tempo e espaço no concernente à exposição dos dois conceitos. E, se ele pretendeu distingui-los, essa distinção estaria marcada por uma confusão. Sobre essa confusão, a primeira frase proporciona uma indicação inicial: o tempo de Kant é um tempo homogêneo. Seguindo a análise dessa crítica, a frase seguinte descreve a duraçâo como composta de momentos que se interpenetram, tais quais cores que se matizam, tais como notas de uma melodia, dirá o autor, em outros lugares. ${ }^{7}$ Vê-se, pois, que o mais importante aqui não é a crítica à homogeneidade do tempo kantiano, embora esta esteja explicitamente colocada, mas a explicitaçáo da ideia de continuidade da duração bergsoniana. As críticas, então, são duas: uma à homogeneidade, outra à divisibilidade do tempo homogêneo. Kant teria, com isso, confundido o tempo com o espaço; e o teria, por consequência, pensado como divisível.

Além de Kant, há, ainda, uma segunda concepção de tempo da qual Bergson se empenha em distinguir-se: a concepção relativista de Einstein. Duração e Simultaneidade termina literalmente assim: "De ce côté, Einstein est le continuateur de Descartes." Essas últimas palavras do livro sugerem que a "imagem" do tempo de Einstein seria, ainda, de certo modo, a tradicional. E o sentido dessa afirmação é dado logo nas primeiras palavras desse livro, no título: Einstein náo lida com o tempo-duração, e sim com o temposimultaneidade. Para o bom entendimento da questão, não se pode deixar, aqui, de fazer uma observaçáo: nesse caso náo se trata da crítica da filosofia à outra filosofia, não se trata da crítica de uma filosofia a uma teoria científica, porém, da própria distinção entre pensamento filosófico e científico. O que se pode ver é que, para Bergson, o que está em questão não é que Einstein, como filósofo, tenha pensado mal o tempo, a partir da filosofia, como Kant o fizera. Vale mesmo dizer que ele o pensou bem, contudo, o fez como cientista. E isso certamente não constitui nominalmente um erro, como no caso de Kant ${ }^{8}$, porque, ao fazê-lo, Einstein fizera o que a ciência deveria de fato fazer. Ora, por mais inovadora que seja uma concepção científica, na história da ciência,

e as justaponha; este acto sui generis parece-se bastante ao que Kant chamava uma forma pura a priori da sensibilidade." (BERGSON, 1988, p. 69).

${ }^{7}$ Ver, por exemplo, Bergson (1988, p. 79).

${ }^{8}$ Cf.: "O erro de Kant foi tomar o tempo por um meio homogêneo [...]" (BERGSON, 1988, p. 159). 
não se pode pretender, não obstante, que esta seja revolucionária na história da filosofia. Para Bergson, a teoria da relatividade não é a aparição de uma nova concepção filosófica do tempo, mas, muito mais, a reiteração de uma concepção científica habitual e mesmo necessária.

Para ilustrar sua exposição, Bergson retoma os resultados da experiência de Michelson-Morley (contração do espaço, dilatação do tempo e dissociação da simultaneidade), e os segue, na teoria da relatividade restrita. Partindo daí, ele percebe que o espaço que se contrai, a simultaneidade que se desloca e o tempo que se dilata pertencem sempre a um sistema de referência virtual, nunca a um sistema real. Se, segundo o relógio do sujeito $S$, pertencente ao sistema R, o sujeito S', pertencente ao sistema R', envelhece mais lentamente que o sujeito $S$ mesmo; ou, se o sujeito $S$, segundo o relógio do sujeito $S$, envelhece mais lentamente que o sujeito $S$ ' mesmo; $S$, segundo seu próprio relógio, envelhece a mesma velocidade que $S^{\prime}$ segundo o seu. Para $S$, assim como para S', seu próprio tempo sempre passa na mesma velocidade, e dois fenômenos simultâneos de seu próprio sistema não poderia jamais transformar-se em sucessivos. Por conseguinte, a dilatação do tempo, como o deslocar da simultaneidade, ocorre sempre no sistema distinto, porém, não para o habitante do sistema distinto, mas para o habitante do próprio sistema. Em outras palavras, o deslocamento da simultaneidade ou a dilatação do tempo exige que não se coloque em nenhum sistema, que nenhum sistema seja o sistema de referência. Se se colocar em quaisquer deles, o tempo cessa de ser relativo. Para ser relativo, o sistema de Einstein exige abster-se de uma decisão: a de habitar um ou outro sistema de referência. O tempo que se dilata é o tempo do sujeito $S$, porém, para o sujeito $S$ ', e não para o sujeito $S$. Com efeito, o tempo que se dilata é um tempo sempre distinto, sempre de outro sistema, sempre virtual. Basta que se habite um sistema, para que este deixe de dilatar-se, basta que o abandone, para que comece a fazê-lo. Já o tempo real, o tempo habitado, este não poderia dilatar-se. E a saída do cientista alemão é não se colocar em nenhum sistema, equiparando, para tanto, realidade e virtualidade. Ora, se isso lhe permite medições mais exatas e uma determinação mais precisa das posiçôes, não se pode dizer, com isso, que seja um erro fazêlo. Todavia, o filósofo, por não poder deixar de lado a diferenciação entre a realidade e virtualidade, se coloca em todos os sistemas ao mesmo tempo, e vê que em nenhum deles o tempo se dilata. A sua preocupação é com o tempo real. E, no tempo real, naquele da vida e da consciência, os fatos sucessivos não poderão tornar-se simultâneos, assim como dois fatos simultâneos não poderão tornar-se sucessivos. Ver-se-á, por conseguinte, que é a presença da 
consciência ou de uma temporalidade psicológica que irá possibilitar a definição da simultaneidade como sendo a relação entre dois ou mais fluxos. E, sendo a simultaneidade fundamentalmente psicológica, não haveria qualquer razão para se separar um tempo do filósofo e um tempo do físico. Para Bergson, essa separação teria sido artificialmente promovida, já que, fundamentalmente, os dois tempos são, em realidade, o mesmo. Fora de uma consciência, só haveria simultaneidade no espaço. Ele irá apontar, ainda, que cabe à ciência o papel de investigar a simultaneidade de dois instantes e que jamais chegaríamos à simultaneidade através do tempo real, ou da duração, posto que "[...] o tempo real não tem instantes" (BERGSON, 2006b, p. 62); o instante aparece, então, como uma "miragem retrospectiva" a que se pode recorrer para medir a duraçáo real; ele é, com efeito, sempre uma virtualidade. Já a duração, por sua vez, é escorregadia a qualquer medida. A saída, então, é a medição do espaço, razão pela qual instante e espaço se tornam uma só coisa, e a simultaneidade dos instantes torna-se fictícia, na falta de um elemento unificador, de uma consciência. Assim, o que se pode notar é que o tempo real não dura nem mais nem menos, porque a duração não comporta nem mais nem menos: não se pode quantificá-lo, não se pode medi-lo. A determinação da dilatação do tempo, tal como a do deslocamento da simultaneidade, exige a medida do tempo, sua divisão e quantificação. Esse, ao que parece, é o sentido da afirmação de Bergson de que Einstein seria aquele que teria levado às últimas consequências uma orientação já iniciada em Descartes. Segue operando com o tempo mensurável e quantificável, isto é, o tempo homogêneo e divisível.

De um modo ou de outro, a crítica que persiste será sempre a mesma: a tradição do pensamento, sobretudo o filosófico, confundira o tempo com o espaço. Em termos já recorrentes, significa que o tempo foi pensado como homogêneo, divisível e/ou simultâneo, conforme o caso. Ante a conceituação da duração de Bergson e da sua distinção em relação ao tempo, é necessário fixar a atenção nesse segundo ponto. E a questão é: pode-se dizer, para todos os casos, que a tradição teria pensado o tempo tal como crê o autor francês? Atentar-se-á, aqui, para o caso estritamente filosófico: o tempo kantiano.

Barthélemy-Madaule (1966, p. 38), em Bergson adversário de Kant, revela a fonte da crítica de Bergson como sendo "a Estética Transcendental". $\mathrm{Na}$ verdade, os argumentos quarto e quinto da Exposiçāo Metafísica destacam, respectivamente: "Tempos diferentes são unicamente partes de um mesmo tempo" e "[...] qualquer grandeza determinada de tempo é somente possível por limitaçóes de um tempo único”. (KANT, 1997, A32, B48) Note-se que 
a Estética Transcendental parece contar com um tempo capaz de ser partido, limitado, sendo, no caso, esse tempo, divisível. Tal fato, portanto, para Bergson, o torna também homogêneo. Ao que tudo indica, parece haver razão na crítica de Bergson: "Le parallélisme est incontestable." ( BARTHÉLEMY-MADAULE, (1966, p. 47).

Sem querer entrar aqui em uma discussão mais abrangente, o que tornaria a duração, frente ao dito tempo homogêneo, uma ideia mais aproximada do tempo real? Ora, Bergson sabe da existência (e até mesmo da utilidade) de um tempo homogêneo e divisível, o tempo da ciência. A crítica está no fato de a tradição filosófica, e em especial Kant, ter privilegiado justamente esse tempo na determinação do conceito. A questão não é, creio que em quaisquer dos casos, o desconhecimento da existência de um "outro" tempo.

O que dá originalidade ao tempo bergsoniano é seu enfoque bem preciso, o qual se abre em duas vias: privilegiar o tempo da vida ante o tempo da ciência e, consequentemente, dar a este uma dimensão ontológica da qual irá depender o resto de seus problemas filosóficos. Assim, a novidade de Bergson é que ele se concentra, fundamentalmente, no tempo da vida, fazendo deste o elemento central de sua filosofia. Vê-se, aqui, o primado ontológico da duração: faz-se do tempo a própria dinâmica do ser, privilegiando, assim, por um lado, o tempo da vida, face ao tempo científico, e fazendo do tempo da vida a dinâmica do ser, a partir da qual se pode explicar o resto dos fenômenos. Há, assim, uma oposição radical entre a "forma" da intuição kantiana, o "tempo espacializado", herdado da mecânica newtoniana, e o que Bergson irá chamar de tempo real ou duração: um tempo no qual os momentos se interpenetram e são qualitativamente distintos uns dos outros.

O que se pode perceber aqui é que, tendo rompido com Kant e toda uma tradição moderna que não teria atentado para a verdadeira natureza do tempo, Bergson não pode, por conseguinte, admitir uma teoria da intuição, bem como uma teoria do conhecimento, daí advinda. Com isso, mesmo não tendo definido, em seu primeiro texto, a intuição como método específico da filosofia que pretende levar a termo, ao posicionar-se contra a ideia de tempo que acompanha o pensamento moderno, Bergson deixa entrever a metafísica que defenderá e que estará fundamentada na experiência real do tempo, possibilitada pelo uso da intuição - intuição intelectual metafísica - como forma de ampliação do campo de percepção, para além de um empirismo restrito. ${ }^{9}$

${ }^{9}$ De fato, "L’empirisme supérieur de Bergson élargit les possibilités de la pensée grace à l’experience de nouvelles possibilités [...] 'l'intuition supérieure' que Kant croyait nécessaire por fonder toute 
Tais posiçốes se confirmam nas afirmaçóes feitas posteriormente, ao analisar o problema da intuição na doutrina kantiana:

\begin{abstract}
Mas essa dualidade de intuição, Kant não queria e, aliás, nem podia admiti-la. Para admiti-la, teria sido preciso ver na duraçáo o tecido mesmo de que é feita a realidade e, por conseguinte, distinguir entre a duração substancial das coisas e o tempo espalhado em espaço [...] Nada de mais contrário à letra, e talvez também ao espírito, da Crítica da razão pura. (BERGSON, 2005, p. 389).
\end{abstract}

Essas afirmaçôes ressaltam a posição de que fora acima de tudo a "descoberta" (ou reinstituição) da duração ou do tempo real que possibilitara ao autor francês uma revisão do estatuto da intuição, dentro da metafísica apresentada por ele como possível. ${ }^{10}$ Depois de ter desqualificado o "tempo formal", não há mais possibilidade de admitir uma intuição de face kantiana. A admissão de tal intuição, calcada em uma visão analítico-científica do tempo, significaria uma insistência no uso dos termos da análise do espaço para descrever a experiência intuitiva do tempo; e, especialmente do ponto de vista do conhecimento, permanecer sujeito às ilusôes, que, por vezes, acompanham tanto a ciência quanto a filosofia, sobretudo nos esforços de descrição do movimento, da vida ou dos estados psicológicos.

O desenvolvimento do argumento bergsoniano atestará que tal caracterização do tempo estará diretamente relacionada com uma experiência relativa, abstrata e insuficiente da realidade, na medida em que oferece desta somente recortes instantâneos (pontos de vista relativos), imóveis, sobre os quais o entendimento poderá aplicar seu aparato analítico. Em contrapartida a essa relativização do conhecimento, Bergson pretende rever o estatuto do tempo e o status da intuição, para daí reinstaurar a metafísica como conhecimento absoluto ou conhecimento do absoluto. Sobre essa intuição, ele questiona, em correspondência com William James: "Se pudéssemos modelar nossa faculdade de intuição sobre a mobilidade do real, a modelagem não seria algo estável, e a verdade - que só pode ser esta própria modelagem - não participaria desta estabilidade?"(BERGSON, 1974, p. 14).

prétendue métaphysique, Bergson (contrairement à Kant) maintient qu'elle existe." (MULLARKEY, 2002, p. 314).

${ }^{10}$ Em outras palavras, “[...] l'intuition de la durée impose à la chronologie de l'œuvre son rythme [...] Elle aura beau ensuite reformer son sens au contact de la durée, elle s'inscrit dans un genre qui la contient et donne à Bergson de s`inscrire lui-même dans l’histoire de la métaphysique." (RIQUIER, 2007, p. 202, 217). 
Para melhor elucidação dos pontos levantados aqui, é preciso recompor mais detidamente as críticas que Bergson desfere contra a Estética kantiana, pois, ao que tudo indica, elas podem sugerir um caminho reflexivo que amplie a compreensão do texto bergsoniano. Além disso, é preciso compreender a que elo correspondem tais críticas, dentro do contexto da apologia do autor francês à metafísica. Porém, é importante buscar antes, no próprio texto kantiano, os elementos motivadores de tais críticas. No prólogo da primeira edição da Crítica da razão pura (1781), Kant (1997, p. AXI) escreve:

É vão, com efeito, afectar indiferença perante semelhante investigação, cujo objecto não pode ser indiferente à natureza humana. Esses pretensos indiferentistas [...] não são capazes de pensar qualquer coisa sem cair, inevitavelmente, em afirmaçōes metafísicas. Porém, essa indiferença, que se produz no meio do florescimento de todas as ciências [...] é um fenômeno digno de atenção e reflexão. Evidentemente que não é efeito de leviandade, mas do juízo amadurecido da época, que já não se deixa seduzir por um saber aparente.

Com um tom marcadamente incisivo, o autor alemão introduz o que será um dos problemas centrais de sua obra, o eixo que articula seu desenvolvimento: a razão não pode permanecer indiferente frente àqueles conhecimentos que são os últimos aos quais se deveria renunciar (conhecimento metafísico). Contudo, com a maturidade alcançada, a razão não pode fugir à necessidade de empreender um esforço de autoconhecimento, devendo mesmo cobrar de si que julgue a si mesma, para que possa legitimar suas pretensôes. $\mathrm{O}$ resultado disso, no respeitante ao valor da metafísica, é suficientemente conhecido, especialmente a subsunção desta à ciência e a interdição do acesso à coisa em si: núcleo da reprovaçáa bergsoniana. Como se sabe, Bergson fundará sua censura ao kantismo em um ponto concreto da formulação de sua doutrina: a vinculação entre metafísica e intuição. Afirma Bergson: "As doutrinas que têm um fundo de intuição escapam à crítica kantiana na exata medida em que são intuitivas; e essas doutrinas são tudo na metafísica." (BERGSON, 2006a, p. 232). O que está em pauta, nessa oposição de Bergson ao kantismo, é a proposição de outra maneira de entender o pensar metafísico, que o tome por algo vivo e ativo, fazendo radicar sua possibilidade na possibilidade real de uma intuição intelectual.

O problema, contudo, está no fato de que, sendo o terreno do saber metafísico o terreno do suprassensível, isso faz com que este seja um saber teoricamente problemático. Na visão de Kant (1997, p. BXIV-XV): 
O destino não foi até hoje favorável que permitisse trilhar o caminho seguro da ciência à metafísica, conhecimento especulativo da razão completamente à parte e que se eleva inteiramente acima das liçóes da experiência [...] devendo, portanto, a razáo ser discípula de si própria; [...] Não há dúvida, pois, que o método tem sido um mero tateio e, o que é pior, um tateio apenas entre simples conceitos.

Nesse excerto, é possível ver explicitamente a situação problemática em que a metafísica se acha, naquele momento: não ter encontrado, ainda, um modo adequado de proceder, razão pela qual tem trabalhado, até então, fundamentada em simples conceitos. Importa notar, aqui, que a funcionalidade da intuição está desde já apontada: com efeito, Kant indicará como utilidade negativa da sua crítica "[...] a de nunca nos atrevermos a ultrapassar com a razão especulativa os limites da experiência” (KANT, 1997, p. BXXIV); tal visão oferece a contrapartida positiva de restringir o uso prático da razão. De fato, afirma Kant, “[...] o pensamento tem sempre que referir-se, finalmente, à intuição, quer directamente (directe), quer por rodeios (indirecte) [mediante certos caracteres] e, por conseguinte, no que respeita a nós, por via da sensibilidade, porque de outro modo nenhum objecto nos pode ser dado." (KANT, 1997, p. A19 B33). Portanto, a possibilidade da metafísica como conhecimento objetivo e, consequentemente, científico radica-se no alcance da intuiçâo, considerada, no caso, como puramente sensível. É possível observar tal posicionamento em um dos mais representativos trechos nos quais esse tema é exposto, na Crítica:

Sejam quais forem o modo e os meios pelos quais um conhecimento se possa referir a objectos, é pela intuição que se relaciona imediatamente com estes e ela é o fim para o qual tende, como meio, todo o pensamento. Esta intuição, porém, apenas se verifica na medida em que objecto nos for dado; o que, por sua vez, só é possível, [pelo menos para nós homens,] se o objecto afectar o espírito de certa maneira. A capacidade de receber representações (receptividade), graças à maneira como somos afectados pelos objectos, denomina-se sensibilidade. Por intermédio, pois, da sensibilidade são-nos dados objectos e só ela nos fornece intuiçôes; mas é o entendimento que pensa esses objectos e é dele que provêm os conceitos. (KANT, 1997, p. A19 B33).

Vê-se, pois, que a intuição é definida aqui, em primeiro lugar, pela imediatez, ou seja, pela referencialidade imediata do conhecimento ao objeto. 
E, se Kant salva a objetividade do conhecimento, através dessa referência a algo, junto ao caráter imediato da intuição aparece um segundo termo, indissociável do primeiro, a receptividade: a intuição é o modo pelo qual o conhecimento se refere imediatamente ao dado. Dessa maneira, em ausência desse dado inicial recebido, a intuição seria ou bem espontaneidade criadora, ou bem uma forma de sentimento subjetivo, algo inacessível e impossível para o homem ou algo irrelevante, no que diz respeito ao conhecimento que deve ser submetido à crítica (conhecimento objetivo e científico). Por outro lado, e em consequência disso, nesse processo de conhecimento, a intuição aparece como meio, em virtude de sua vinculação com a sensibilidade (capacidade de receber representaçôes), garantindo a legitimidade da atividade espontânea do entendimento, de onde procedem os conceitos: o processo de constituição dos objetos haverá de sustentar-se na intuiçáo. Até aqui, por conseguinte, a teoria kantiana da intuição se caracteriza pela imediatez e receptividade; constitui parte de um processo vinculado à sensibilidade (que é receptiva), sendo o entendimento (espontaneidade) a culminação do mesmo; e, por último, se trata de uma forma de representação. São pontos, como se sabe, de grande relevância para a crítica bergsoniana, já que este só admite a caracterização da intuição pela imediatez, rechaçando, portanto, os demais pontos. Em seu primeiro momento, desse modo, a intuição aparece não como receptividade, mas como vivência; não tem um caráter representativo, muito pelo contrário, ela se define como contato ou convivência - simpática - com seu objeto.

Ponto importante dentro da censura bergsoniana a Kant é a adesão, por parte deste, ao modelo analítico-científico no momento de levar a termo sua filosofia transcendental, o que teria feito com que esta permanecesse inevitavelmente marcada pela relaçáo com a ciência, colocando esta última como paradigma a ser seguido e apontando para uma unidade do saber na ciência. De fato, essa operação é focalizada de forma positiva, na obra de Kant, especialmente quando confrontada com a atitude bergsoniana que, desde $A$ Evolução Criadora, postulará a distinção necessária entre filosofia e ciência, ao menos em termos de métodos e objetos específicos.

É bom ter em mente, mais uma vez, que o sentido da objeção bergsoniana se dirige fundamentalmente e tem como raiz a valorização ontológica da temporalidade. Vale ressaltar, ainda, que essa objeção se vincula com o terceiro dos pressupostos que operam na exposição kantiana: o conhecimento do "Eu", a função da experiência interna e a psicologia de caráter associacionista que subjaz na Crítica. Dando encaminhamento, tem-se a afirmação de Kant em 
relação ao tempo: "O tempo não é um conceito empírico que derive de uma experiência qualquer. Porque nem a simultaneidade nem a sucessão surgiriam na percepção se a representação do tempo não fosse o seu fundamento a priori." (KANT, 1997, p. A31 B46). Nessa afirmação, é possível ver expressa com clareza a atitude do autor, no momento de iniciar sua análise crítica: "[...] o tempo não é um conceito empírico", não pertence, pois, às coisas; é, com efeito, como referirá em outro momento, "[...] a forma real da intuição interna”, cujo caráter a priori garante os valores de universalidade, necessidade e certeza no conhecimento sintético dos fenômenos. O tratamento do tema do tempo, na filosofia transcendental kantiana, se apoiaria no pressuposto de que a ciência, com as características adquiridas em sua orientação moderna, constituiria o modelo paradigmático do conhecimento. Ora, assim considerado, o tempo aparece como condiçâo subjetiva sob a qual tem lugar toda e qualquer intuição e, sendo a priori, é anterior aos objetos em sua representação; é, também, a forma pela qual é possível ao sujeito intuir a si mesmo e ao seu estado interno, ${ }^{11}$ o que o póe num papel decisivo em relação ao tema do conhecimento do "Eu". Esse tema haverá de ser um dos pontos centrais da oposição bergsoniana ao enfoque metafísico de Kant, sobretudo porque, na Crítica, "[...] todos os objetos dos sentidos são puros fenômenos” (KANT, 1997, p. A49). É importante notar o fato de o sujeito kantiano representar a si mesmo como fenômeno na intuição, isto é, como algo relativo, posição corroborada por alguns pontos: $1^{\circ}$ ) a distinção entre intuição e pensamento, sendo a primeira receptividade imediata, enquanto o pensar, como atividade constitutiva do sujeito, exige a mediação; $2^{\circ}$ ) a vinculação entre a intuição e a sensibilidade: uma vez estabelecida a distinção anterior, só o pensamento pode ser definido por essa espontaneidade, e a intuição, pelo contrário, é representação e implica a presença de algo pelo qual o sujeito é afetado (no caso do sentido interno, esse algo é sua própria atividade), permanecendo excluída uma intuiçáo intelectual; (KANT, 1997, p. A39-40, B56-57). 3º a análise desse dinamismo afeta exclusivamente o conhecimento objetivo, abdicando-se de outras formas de acesso ao real que, dessa perspectiva, tem seu valor ignorado; $4^{\circ}$ ) a intuição que o sujeito tem de si apresenta um caráter unificante e sintetizador da diversidade dada à sensibilidade. Sobre isso, afirma Kant (1997, p. B68):

11 “[...] impugnamos qualquer pretensão do tempo a uma realidade absoluta, como se esse tempo, sem atender à forma da nossa intuiçấo sensível, pertencesse pura e simplesmente às coisas, como sua condiçấo ou propriedade. Tais propriedades, que pertencem às coisas em si, nuca podem ser dadas através do sentido [...] O tempo é, sem dúvida, algo real, a saber, a forma real da intuição interna." (KANT, 1997, p. A36-37, B52). 
A consciência de si mesmo (a apercepção) é a representação simples do eu e se, por ela só, nos fosse dada, espontaneamente, todo o diverso que se encontra no sujeito, a intuição interna seria então intelectual. No homem, esta consciência exige uma percepção interna do diverso, que é previamente dado no sujeito, e a maneira como é dado no espírito, sem espontaneidade, deve, em virtude dessa diferença, chamar-se sensibilidade.

Admitida a diversidade do dado, a atividade unificante do sujeito vem a ser o elemento fundamental do processo de conhecimento, levado a cabo em todos os níveis, desde a intuição (KANT, 1997, p. B130) até a unidade sintética da apercepção: "[...] ponto mais elevado a que se tem de suspender todo uso do entendimento, toda a própria lógica e, de acordo com esta, a filosofia transcendental: esta faculdade é o próprio entendimento." (KANT, 1997, p. B134, nota).

O que importa, efetivamente, é notar que a metafísica para Kant abrange o âmbito do suprassensível, motivo pelo qual se apresenta como uma forma de saber "problemática", cuja justificação e fundamentação exigem uma crítica da razão. Já Bergson, pelo contrário, com a intenção de recuperar a metafísica como saber, parte de uma afirmação de princípio: a metafísica é experiência, seu campo é a duração e a vida e sua principal tarefa consiste em aproximar-se desta. Essa afirmação da vida e dos fatos, anterior à análise gnosiológica, vem a ser um dos pontos centrais da contraposição de Bergson ao kantismo, como bem o mostrou Franklin Leopoldo e Silva. Analisando a relaçáo entre os dois pensadores, ele aponta para o fato de que a censura de Bergson a Kant se funda no fato de este não ter notado que a ciência se tornava "[...] cada vez menos objetiva, cada vez mais simbólica, à medida que ia do físico ao vital, do vital para o psíquico." (BERGSON, 2005, p. 387). E Bergson (2006a, p.72) completa:

Todo alvo da Crítica da razão pura, com feito, é explicar como uma ordem definida vem se acrescentar à materiais que são supostos incoerentes. E sabe-se com que preço ela nos faz pagar essa explicação: o espírito humano imporia sua forma a uma "diversidade sensível" vinda não se sabe de onde, a ordem que encontramos nas coisas seria aquela que nós mesmos pomos nelas. De modo que a ciência seria legítima, mas relativa à nossa faculdade de conhecer, e a metafísica impossível [...].

Os argumentos bergsonianos sugerem que, como desdobramento da aceitaçáo da ordem como algo imposto pela atividade formalizadora do 
sujeito, se teria a admissão da relatividade do conhecimento conferida tanto à ciência como à metafísica. Além disso, como frisado anteriormente, quando Kant aborda o problema do alcance do conhecimento e da possibilidade do conhecimento metafísico, ele o faz tendo o modelo científico de conhecimento como parâmetro. De todo modo, à metafísica caberá transcender os conceitos e chegar à intuição direta, se quiser se afirmar como uma forma de conhecimento que pretende passar-se de simbolos (BERGSON, 1969, p. 182). Com isso, o saber metafísico se oporia ao conhecimento representativo e simbólico, em virtude de seu caráter absoluto; e, posto que o absoluto, para Bergson, constitui o "interior" das coisas, seu método é a intuição metafísica, condição mesma para o contato direto com o real. Ora, visto que essa intuição se contrapóe à abordagem científica, ao senso comum e à ação, uma metafísica que parta dessa intuição haverá de exigir um esforço para remontar o que Bergson denomina a marcha natural do pensamento ou "[...] a direção habitual do trabalho do pensamento" (BERGSON, 2006a, p. 221). Justamente aqui, nessa maneira de entender a metafísica, reside, em grande medida, a oposição a Kant, tomado como aquele que conduziu a metafísica ao "[...] limite extremo do simbolismo" (BERGSON, 2006a, p. 228). ${ }^{12}$ Por outro lado, frente à razão pura kantiana, o autor irá sustentar uma noção de conhecimento dada a partir de um sujeito aberto ao mundo, originado como homo faber $^{13}$, que aparece na linha da evolução percorrida pela inteligência e que, portanto, vê-se submetido às exigências da lógica e da linguagem e, respondendo a estas, recebe suas determinaçóes (BERGSON, 2005, p. 151). $\mathrm{O}$ “apriorismo" kantiano experimenta, como se pode ver, uma inversão.

Por outro lado, as análises "psicológicas" de Bergson o conduzem à observação de que a vida psíquica, constituindo a "interioridade” do sujeito, é

\footnotetext{
${ }^{12}$ Vale lembrar, aqui, uma passagem do livro de Franklin Leopoldo e Silva, a qual expôe os motivos dessa afirmação de Bergson: em Kant, "[a] intuição de elementos descontínuos na forma espacial e temporal é o fundamento material das relaçóes intelectuais. Na medida em que a forma impóe ao conhecimento um caráter fenomênico, tais relaçóes nunca poderão ultrapassar o âmbito do relativo. Ora, se a matéria do conhecimento é o mesmo que a forma sensível pela qual a percebemos [...] O sujeito tem de ser exterior ao objeto para que este recupere a autonomia [...] por isso Kant nấo pode conceber nem intuição interna enquanto coincidência consigo próprio, nem intuiçáo intelectual enquanto captação do objeto para além da articulação intelectual [...] O conteúdo tem de ser radicalmente estranho. E como a mediação que leva o dado dessa estranheza ao reduto lógico que lhe conferirá familiaridade intelectual é a forma, só o fenômeno externo pode ser apreendido." (LEOPOLDO E SILVA, !994, p. 76-77).

13 “[...] são bem conhecidas as consideraçôes de Bergson acerca da precedência do homo faber sobre o Homo sapiens. Portanto, o que vimos saber pela inteligência acerca do mundo é muito mais aquilo de que necessitamos para viver dele do que para pensar sobre ele." (LEOPOLDO E SILVA, 1983, p. 22-23).
} 
um processo dinâmico, cuja unidade se deve à interpenetração de seus estados, revelando, portanto, um "eu" de caráter qualitativamente heterogêneo, o qual, em virtude e como expressão de sua estrutura e atividade, "[...] toca o mundo exterior superficialmente" (BERGSON, 1988, p. 88), dificultando o acesso intuitivo à imediatez de si mesmo. E, nessa direção, a oposição ao texto de Kant toma uma forma mais radical ainda. Isso é posto de modo bem manifesto, em $O$ pensamento e o movente:

Kant havia estabelecido, dizia-se, que nosso pensamento se exerce sobre uma matéria espalhada [...] a "coisa em si" escapa-nos; seria preciso, para atingi-lo uma faculdade intuitiva que não possuímos. Pelo contrário, resultava de nossa análise que pelo menos uma parte da realidade, nossa pessoa, pode ser recuperada em sua pureza natural [...] Nossa pessoa nos aparece como ela é "em si" assim que nos libertamos de hábitos que foram contraídos para nossa maior comodidade. (BERGSON, 2006a, p. 24).

De todo modo, o que mais interessa, aqui, é verificar como Bergson estabelece sua metafísica, através de indicaçóes claramente traçadas: frente a Kant, ele se situa nos fatos, com a intenção de edificar uma metafísica capaz de chegar cada vez mais fundo, em um esforço contínuo, progressivo e organizado de todos os filósofos unidos no mesmo respeito à experiência; e propóe, ou melhor, exige uma adesão plena à realidade a se inserir. Tal metafísica, afirma Worms, "[...] est un retour à l'immédiat et au donné; elle est donc à la fois critique et intuitive: recherche de la coïncidence entre le savoir et son objet, de la réalité que nous expérimentons dans l’acte pur de la perception, ou de l'intuition." (WORMS, 2004, p. 140).

Tal posição expressa a afirmação da primazia do real e tenta afastar desse plano toda tentativa de relativização: a metafísica, pelo recurso metodológico à intuição, haverá de ser um saber absoluto do absoluto, o qual, evitando a mediação conceitual, entra em uma identificação com o núcleo da realidade. Intuição "[...] significa primeiro consciência, mas consciência imediata, visão que mal se distingue do objeto visto, conhecimento que é contato e mesmo coincidência” (BERGSON, 2006a, p. 29), razão pela qual a intuição recai, a princípio, na própria consciência e, em seguida, por simetria, no impulso vital. ${ }^{14}$ Finalmente, à metafísica será atribuída a função de ultrapassar o âmbito do simbólico (passar-se de simbolos), no qual se desenvolve não só a ciência, mas ${ }_{14}$ Afinal, "[...] a vida é um evento psicológico, ou seja, algo exatamente da mesma natureza que
qualquer uma de nossas sensaçóes". (MANIGLIER, 2009, p. 75-110). 
a vida prática em geral. Nesse sentido, veem-se fixados, aqui, dois modos de conhecer, um por conceitos, outro por intuiçẫo direta; e a inteligência, por seu apelo ao conceito, permanece vinculada à prática e à ação exercida sobre a matéria. Em torno desse ponto se concretiza novamente a crítica de Bergson a Kant:

Pois para ir até a intuição não é necessário transportar-se para fora do domínio dos sentidos e da consciência. O erro de Kant foi acreditar que isso fosse necessário. Após ter provado por argumentos decisivos que nuca nenhum esforço dialético irá nos introduzir no além e que uma metafísica eficaz seria necessariamente uma metafísica intuitiva, acrescentou que essa intuição nos falta e que essa metafísica é impossível. Sê-lo-ia, com efeito, caso não houvesse outro tempo e outra mudança além daqueles que Kant percebeu [...] pois nossa percepçáo usual não poderia sair do tempo nem apreender algo diferente da mudança. Mas o tempo no qual permanecemos naturalmente instalados, a mudança que normalmente temos em mira são um tempo e uma mudança que nossos sentidos e nossa consciência reduziram a pó para facilitar nossa ação sobre as coisas. Desfaçamos o que estes fizeram, reconduzamos nossa percepção às suas origens e teremos um conhecimento de um novo gênero sem ter precisado recorrer a novas faculdades. (BERGSON, 2006a, p. 147).

Ressaltada no argumento de Bergson está a proposição de que se Kant negara a intuição metafísica, o que se deve, no limite, ao fato de ele não ter compreendido que o tempo considerado em sua Crítica advém do ato habitual do entendimento trabalhando sobre o fantasma das coisas. $\mathrm{O}$ autor alemão teria permanecido, com isso, preso à ilusáo natural ocasionada pelo próprio trabalho da inteligência, o qual tende, pela necessidade prática, a "espacializar" a duração. ${ }^{15} \mathrm{~A}$ intuição, nesse sentido, exige uma "ultrapassagem" da inteligência e dos hábitos que vigoram na maneira pela qual se pode conhecer, hábitos contraídos na ação e que, ao reaparecer na especulação, criam problemas insolúveis e traz a relatividade ao interior do conhecimento. Contudo, defende Bergson (1999, p. 216):

Nosso conhecimento das coisas já não seria então relativo à estrutura fundamental de nosso espírito, mas somente a seus hábitos superficiais e adquiridos [...] Desfazendo o que essas necessidades fizeram, restabeleceríamos a intuição em sua pureza primeira e retomaríamos contato com o real.

\footnotetext{
15 "A tese geral de Bergson é bem conhecida: nós projetamos sobre a duração verdadeira, infinitamente móvel, o espaço no qual nós vivemos visando a comodidade social.” (VIEILLARD-BARON, 1991, p. 58).
} 
Essa visão da intuição se mostra, com efeito, vinculada e articulada com uma zona problemática que deixa entrever o alcance da teoria do conhecimento bergsoniana: a princípio, como uma experiência interna e, em sua utilização metodológica, a intuição parece encerrar uma dicotomia, apresenta na atividade filosófica um caráter de originariedade, sendo o requisito e pressuposto inicial da filosofia e, por ser originária, não se deixa tomar por casual (e, de certo modo, nem sequer por espontânea, no sentido rigoroso do termo), posto que exige um esforço de preparação prévia direcionado à eliminação das mediaçóes impostas pelo pensamento conceitual. Daí a afirmação de Bergson de que sua intuição metafísica, habitualmente caracterizada como vivência, sentimento etc., é, na verdade, também, reflexâo. ${ }^{16} \mathrm{~A}$ intuição metafísica é reflexâo, na medida em que se trata de um ato (disposiçáo) mediante o qual é possível ultrapassar a mediação do conceito e se transportar à interioridade do objeto para coincidir com ele.

Como últimas consideraçôes, o que se pode assinalar é que a tese fundamental da teoria do conhecimento bergsoniana se firma nos seguintes pontos: $1^{\circ}$ ) como ato de identificaçáo ou coincidência, como contato, como um "instalar-se em", a intuição apresenta uma dimensão ontológica que, por um lado, só adquire sentido pela afirmação da existência de um devir vital que é a duração. Por outro, tem a duração como o que constitui a natureza do sujeito e o que possibilita a intuição como plena imediatez; 20) o caráter imediato da intuição não elimina o esforço reflexivo, posto que se trata de uma ação que se realiza em um "eu" entendido como sujeito capaz de, mediante singular disposição, se instalar no devir, na duração, na vida, ${ }^{17}$ e posto que, como método, ela deve ser estendida a qualquer um que se empenhe no esforço de conhecer.

MASCARENHAS, Aristeu. Bergson and Kant: the problem of time and the limits of intuition. Trans/form/ação, Marília, v. 40, n. 2, p. 103-124, Abr./Jun., 2017.

\footnotetext{
${ }^{16}$ Afirma Bergson (2006, p.99): “Nada diremos acerca daquele que pretende que nossa 'intuiçāo' seja instinto ou sentimento [...] nossa intuição é reflexão".

${ }^{17}$ Esses pontos destacam o caráter aparentemente "paradoxal" da intuição, pois, se, por um lado, a experiência intuitiva é vinculada a uma simpatia direta e irrefletida, constante nos grandes "gênios" e "místicos", por outro, ela é mostrada como uma experiência acessível a "todos os homens", na medida em que é método ou disposição reflexiva adotada diante do objeto.
} 
ABstract: This text aims to analyze intuition, the specificities of the Bergsonian definitions relevant to it, and their distinctions relative to the modern view. Above all, we discuss the doctrine of Kant and seek to show Bergson's points of rupture and advancement in relation to this conception. What is noticeable at first glance is how Bergson's work is in a certain way intimately linked to some classical themes of the theory of knowledge already extensively treated in Kant's work. Kant is present from the beginning of Bergson's thought, ever since his An Essay on the Immediate Data of Consciousness, and his influence extends through almost all of Bergson's work. In fact, if one approaches the texts of Bergson in terms of his references to the history of philosophy, it is no doubt Kant who appears as the great interlocutor, in most cases advancing a critique that can be extended to the whole philosophical tradition, especially to that part which would subjugate metaphysics to the methods and orientations of science. It is natural, indeed, that the author of the Critique of Pure Reason emerges as an important character in Bergson's work. Kant's thinking appeared at an important moment in terms of the "directions" of philosophy, especially with regard to the attainment of metaphysics. Bergson expressed in his doctrine an effort to reclaim the rightful place of metaphysics, even extending its reach beyond the limits of scientific analysis, and thus it is certain that he would encounter Kant in his investigations.

KeYwords: Bergson. Kant. Intuition. Real time. Metaphysics.

\section{REFERÊNCIAS}

BARTHÉLEMY-MADAULE, M. Bergson adversaire de Kant: étude critique de a conception bergsonienne du kantisme suivie d'une bibliographie kantienne. Paris: Presses Universitaires de France, 1966.

BERGSON, H. Carta de Bergson a William James, de 27 de junho de 1907. In: Cartas, conferências e outros escritos. São Paulo: Nova Aguilar, 1974. p. 14 (Os Pensadores). . Ensaio sobre os dados imediatos da consciência. Lisboa: Ediçōes 70, 1988. 2005. . A Evolução criadora. Tradução de Bento Prado Neto. São Paulo: Martins Fontes,

. O Pensamento e o movente: ensaios e conferências. Tradução de Bento Prado Neto. São Paulo: Martins Fontes, 2006a.

. Duração e simultaneidade. Tradução de Cláudia Berliner. São Paulo: Martins Fontes, 2006b.

. Matéria e memória: ensaio sobre a relação do corpo com o espírito. Tradução de Paulo Neves. 2. ed. São Paulo: Martins Fontes, 1999. (Tópicos).

DELEUZE, G. Bergsonismo. Tradução de Luiz Orlandi. Sáo Paulo: Ed. 34, 1999.

KANT, I. Crítica da razão pura. Tradução de A. Morujão. Lisboa: Fundação Calouste Gulbenkian, 1997.

LEOPOLDO E SILVA, F. Bergson e Kant. Cadernos de História e Filosofia da Ciência, Campinas, v. 5, p. 19-28, 1983.

. Intuição e discurso filosófico. São Paulo: Loyola,1994. 
MANIGLIER, P. Bergson estruturalista? In: PINTO, D. C. M.; MARQUES, S. T. (Ed.). Henri Bergson: crítica do negativo e pensamento em duração. São Paulo: Alameda, 2009. p. 75-109.

MULLARKEY, J. La naturalisation de la métaphysique. In: WORMS, F. Annales bergsoniennes I. Paris: Presses Universitaires de France, 2002. p. 309-327.

PRADO JÚNIOR, B. Presença e campo transcendental. São Paulo: EDUSP, 1989.

RIQUIER, C. Intuition et méthode che Bergson. Revue Trans-Paraître: L'Intuition, n.1, p.189-218, 2007.

VIEILlARD-BARON, J. L. Bergson. Paris: Presses Universitaires de France, 1991.

WORMS, F. Le vocabulaire de Bergson. Paris: Ellipses, 2000.

Bergson ou les deux sens de la vie. Paris: Presses Universitaires de France, 2004.

Recebido em 10/12/2016

Aceito em 20/01/2017 
MASCARENHAS, A. 